\title{
MORPHOMETRIC ANALYSIS OF THE HUMAN SPLEEN
}

\author{
Prerna Jagdish ${ }^{1}$, R. K. Ashoka ${ }^{2}$
}

${ }_{1}^{1}$ Assistant Professor, Department of Anatomy, K. D. Medical College Hospital and Research Center, Mathura, Uttar Pradesh, India. 2Professor and HOD, Department of Anatomy, K. D. Medical College Hospital and Research Center, Mathura, Uttar Pradesh, India.

\section{BACKGROUND}

ABSTRACT

With respect to its size, shape, weight, notches \& fissures, spleen is a highly variable organ. It is otherwise very difficult to analyse whether the spleen is normal or abnormal on the basis of its shape; therefore this study has been undertaken to find out percentage of various shapes and other morphometrical parameters of spleen. Accurate knowledge of splenic morphology is essential prior to performing any surgical procedure or making any radiological interpretation with regard to spleen as it reveals many variations in shape, size, notches \& fissures.

\section{MATERIALS AND METHODS}

The present study is a descriptive study conducted in the Department of Anatomy, K. D. Medical College, Mathura, U.P. 60 adult human cadaveric spleens were included. Sexual dimorphism was excluded from the research. The spleens were dissected from the abdominal cavity and a morphometric analysis was done with the help of digital sliding calipers. Data obtained was compared with data available from previous studies after its tabulation and statistical analysis.

\section{RESULTS}

60 human spleens were morphologically analysed in detail. Wedge-shaped spleens were most commonly noted. Mean length was calculated to be about $10.5 \mathrm{~cm}$. Mean breadth was calculated to be about $7.5 \mathrm{~cm}$. Mean width was calculated to be about $4.25 \mathrm{~cm}$.

\section{CONCLUSION}

Studies on the morphometry of spleen will be of interest not only from academic point of view but also for operating surgeons and interventional radiologists. Detailed knowledge on spleen is important to avoid and prevent any complications and to obtain a good operative, as well as diagnostic intervention.

\section{KEY WORDS}

Spleen, Morphometry, Haemo-Lymphoid.

HOW TO CITE THIS ARTICLE: Jagdish P, Ashoka RK. Morphometric analysis of the human spleen. J. Evolution Med. Dent. Sci. 2018;7(46):5011-5014, DOI: 10.14260/jemds/2018/1115

\section{BACKGROUND}

Spleen is an encapsulated haemo-lymphoid organ composed of vascular and lymphoid tissue. It holds a great clinical importance because of its dual haematological and immunological role in the human body. Of the nine abdominal quadrants, it is located in the left hypochondriac quadrant. It lies roughly between fundus of stomach and diaphragm. Its shape is highly variable and varies from a wedge to a tetrahedron. ${ }^{1}$ During the foetal life it serves as an important function of haematopoiesis. It acts as a filter of blood. The organ consists of only the efferent lymphatic vasculature. The phagocytes in the organ are responsible in clearing away the cell debris, ageing erythrocytes, remaining blood cells and microorganisms also. Spleen produces lymphocytes which take part in various immune responses of the body. As lymphopoiesis continues throughout life in a healthy human body therefore spleen holds a great role in providing immunity to the body. 2,3

'Financial or Other Competing Interest': None.

Submission 27-07-2018, Peer Review 23-10-2018,

Acceptance 31-10-2018, Published 12-11-2018.

Corresponding Author:

Dr. Prerna Jagdish,

Assistant Professor

Department of Anatomy,

K. D. Medical College Hospital and Research Center,

Mathura, Uttar Pradesh, India.

E-mail: prerna.jagdish27@gmail.com

DOI: $10.14260 /$ jemds/2018/1115
The spleen is enclosed by a capsule in all mammals. This capsule presents regions of variable thickness. ${ }^{4}$ The capsule at specific regions invaginates the parenchyma of the organ in form of trabeculae. The tissue between the capsule and trabeculae forms the splenic cords or pulp. This splenic pulp or cord can be categorized on its histological appearance as red or white pulp and takes upon either. Splenic red pulp is responsible for storage and the white pulp has a defensive function. ${ }^{5}$ Characteristic notches are seen on the superior border in fetal spleen, nearer to the anterior end. The lobulated form of spleen may sometimes persist in the form of deep notch commonly on the superior border or as fissures on its surfaces. During radiological examinations, the presence of such notches or fissures in the adult spleen may be misinterpreted as splenic injury.6,7

\section{MATERIALS \& METHODS}

Our current study was a descriptive study conducted in the Department of Anatomy, K.D. Medical College, Mathura, U.P. 60 adult human cadaveric spleens were included. Sexual dimorphism was excluded from the research. The spleens were dissected from the abdominal cavity. At first the spleen was detached from all its attachments then the splenic vessels were identified. After identification the splenic vessels were ligated near the hilum and were cut. Now the spleen could be removed carefully. After removal, the spleen was washed in tap water to clean and debris and fatty tissue. The spleens were placed on clean dissection trays and shapes of the spleen were noted under bright dissection lamp. The 
spleens were weighed using an electronic weighing machine. Splenic poles, borders and surfaces were determined, and morphometric analysis was made with the help of digital sliding calipers. The maximum distance between the anterior and posterior pole was taken as length, the maximum distance between the superior and inferior border was taken as bread and the maximum width of spleen was also measured. The data obtained was compared to the previously available studies after its careful tabulation and statistical analysis.

\section{RESULTS}

In the current study, 60 human spleens were morphologically analysed in detail. The specimens were showed four different shapes, of which wedge-shaped spleens were most commonly noted. Wedge (43.3\%), tetrahedral (28.3), triangular (15\%) and oval $(2 \%)$ shapes were noted. All the spleens were weighed. $48.3 \%$ spleens weighed between 100 to $150 \mathrm{gm}$. $33.3 \%$ spleens weighed between 51 to $100 \mathrm{gm}$.

\begin{tabular}{|c|c|c|}
\hline Shape & No. of Specimen & Percentage (\%) \\
\hline Wedge & 26 & 43.3 \\
\hline Tetrahedral & 17 & 28.3 \\
\hline Triangular & 15 & 25 \\
\hline Oval & 2 & 3 \\
\hline \multicolumn{2}{|c|}{ Table 1. Shape of Spleen } \\
\hline
\end{tabular}

\begin{tabular}{|c|c|c|}
\hline Weight (gms) & No. of Specimen & Percentage (\%) \\
\hline $0-50$ & 1 & 1.6 \\
\hline $51-100$ & 20 & 33.3 \\
\hline $101-150$ & 29 & 48.3 \\
\hline $151-200$ & 6 & 10 \\
\hline $201-250$ & 3 & 5 \\
\hline $251-300$ & 1 & 1.6 \\
\hline \multicolumn{3}{|c|}{ Table 2. Weight of Spleen } \\
\hline
\end{tabular}

\begin{tabular}{|c|c|c|}
\hline Length (cm) & No. of Specimen & Percentage (\%) \\
\hline 7.0 & 1 & 1.6 \\
\hline 7.5 & 0 & 0 \\
\hline 8.0 & 3 & 5 \\
\hline 8.5 & 1 & 1.6 \\
\hline 9.0 & 7 & 11.6 \\
\hline 9.5 & 6 & 10 \\
\hline 10.0 & 8 & 13.3 \\
\hline 10.5 & 8 & 13.3 \\
\hline 11.0 & 8 & 13.3 \\
\hline 11.5 & 8 & 13.3 \\
\hline 12.0 & 2 & 3 \\
\hline 12.5 & 5 & 8.3 \\
\hline 13.0 & 2 & 3 \\
\hline 13.5 & 0 & 0 \\
\hline 14.0 & 1 & 1.6 \\
\hline
\end{tabular}

In this study, variations were seen in the length of spleen. Length was seen to vary from 7.0 to $14.0 \mathrm{~cm}$. Majority of spleens measured $10-11.5 \mathrm{~cm}$ in length. Mean length was calculated to be about $10.5 \mathrm{~cm}$, median was found to be 10.5 $\mathrm{cm}$ with a standard deviation of 2.236 .

\section{Range}

- Minimum Length $-7.0 \mathrm{~cm}$

- Maximum Length $-14.0 \mathrm{~cm}$

- $\quad$ Mean Length $-10.5 \mathrm{~cm}$

- $\quad \pm$ S.D. $-2.236 \mathrm{~cm}$

\begin{tabular}{|c|c|c|}
\hline Breadth (cm) & No. of Specimen & Percentage (\%) \\
\hline 4.0 & 1 & 1.6 \\
\hline 4.5 & 0 & 0 \\
\hline 5.0 & 2 & 3 \\
\hline 5.5 & 1 & 1.6 \\
\hline 6.0 & 3 & 5 \\
\hline 6.5 & 4 & 6.6 \\
\hline 7.0 & 5 & 8.3 \\
\hline 7.5 & 4 & 6.6 \\
\hline 8.0 & 10 & 16.6 \\
\hline 8.5 & 11 & 18.3 \\
\hline 9.0 & 5 & 8.3 \\
\hline 9.5 & 8 & 13.3 \\
\hline 10.0 & 4 & 6.6 \\
\hline 10.5 & 0 & 0 \\
\hline 11.0 & 2 & 3 \\
\hline \multicolumn{3}{|c|}{ Table 4. Breadth of Spleen } \\
\hline
\end{tabular}

Breadth was seen to vary from 4.0 to $11.0 \mathrm{~cm}$. Maximum breadth noted in 60 spleens was $8.5 \mathrm{~cm}$ (18.3\%). Mean breadth was calculated to be about $7.5 \mathrm{~cm}$, median was found to be $7.5 \mathrm{~cm}$ with a standard deviation of 2.236 .

\section{Range}

- Minimum breadth $-4.0 \mathrm{~cm}$

- Maximum breadth $-11.0 \mathrm{~cm}$

- Mean Breadth $-7.5 \mathrm{~cm}$

- $\quad \pm$ S.D. $-2.236 \mathrm{~cm}$

\begin{tabular}{|c|c|c|}
\hline Width (cm) & No. of Specimen & Percentage (\%) \\
\hline 2.0 & 1 & 1.6 \\
\hline 2.5 & 0 & 0 \\
\hline 3.0 & 4 & 6.6 \\
\hline 3.5 & 15 & 25 \\
\hline 4.0 & 22 & 36.6 \\
\hline 4.5 & 11 & 18.3 \\
\hline 5.0 & 6 & 10 \\
\hline 5.5 & 0 & 0 \\
\hline 6.0 & 0 & 0 \\
\hline 6.5 & 1 & 1.6 \\
\hline \multicolumn{3}{|c|}{ Table 5. Width of Spleen } \\
\hline \multicolumn{3}{|c}{} \\
\hline
\end{tabular}

Width was seen to vary from 2.0 to $6.5 \mathrm{~cm}$. The maximum width was recorded to be $4 \mathrm{~cm}$ in $36.6 \%$ of cases. Mean width was calculated to be about $4.25 \mathrm{~cm}$, median was found to be $4.25 \mathrm{~cm}$ with a standard deviation of 1.513 .

\section{Range}

- Minimum Width $-2.0 \mathrm{~cm}$

- Maximum Width $-6.5 \mathrm{~cm}$

- Mean Width $-4.25 \mathrm{~cm}$

- $\quad \pm$ S.D. $-1.513 \mathrm{~cm}$

\section{DISCUSSION}

Spleen is a haemo-lymphoid organ. It is a highly vascular and well encapsulated organ. It is the largest lymphoid organ. It plays a central role in the defense mechanism of the body. 
The role of spleen as a blood filter was found to be very significant by a series of animal experiments and patients' follow up studies which revealed actual importance of spleen in protection from blood borne sepsis ${ }^{8}$. It has two surfaces namely diaphragmatic and visceral surfaces and three borders namely superior, intermediate and inferior border and four impressions namely gastric impression, renal impression, colic impression, pancreatic impression. Spleen shows one or two notches on superior border.9,10,11,12 In the current study length, breadth and width of 60 human spleens has been noted. Spleen, showing vast variations in dimensions and morphology, its morphometric study is the need of present anatomical scene.

Spleen is a highly variable organ with respect to size, shape, weight, notches \& fissures. It is very difficult to analyse whether the spleen is normal or abnormal on the basis of its shape so this study has been undertaken to find out percentage of various shapes of spleen and its morphometry. It is the need of the present era to have accurate knowledge of morphology of spleen as it reveals ample of variations in its shape, size, about notches \& fissures.

All the parameters of liver and spleen are important for ultrasound examination. Organ dimensions have also been linked to weight of individual. Anomalies of spleen often remain undetected as they are asymptomatic. 13 48.3\% spleens weighed between 100 to 150 gm which appears close to the normal range of 80 to $300 \mathrm{gm}$. $33.3 \%$ spleens weighed between 51 to $100 \mathrm{gm}$. Chaware et al conducted a research to study the morphometry of spleen, out of 111 studied spleens, $61.2 \%$ spleens were wedge shaped. ${ }^{14}$ This is in concordance with findings in current study where $43.3 \%$ cases were wedge shaped. In a study conducted by Setty et al, the weight of the spleen varied from 30 to $325 \mathrm{gms}$, with average of 138.40 gms. ${ }^{15}$

Measurement of the splenic length during routine clinical examination is a good indicator of actual splenic size.16 Splenomegaly is an important diagnostic clue to underlying disorder. ${ }^{17}$ The spleen is affected by a number of disorders. The abnormalities of the cells that populate within the spleen are seen in diseases like malaria, kala azar etc. ${ }^{18}$ Disturbance of storage function of the spleen is seen in sarcoidosis, leukaemia etc. ${ }^{19}$ In such cases splenectomy or removal of the spleen is the choice of treatment. Any accessory splenic tissue if present, must be removed as well during operation; otherwise the disease may recur. ${ }^{18}$ Therefore, detail morphological knowledge is essential for diagnosis and management of splenic diseases. In this study, variations were seen in the length of spleen. Length was seen to vary from 7.0 to $14.0 \mathrm{~cm}$. Majority of spleens measured $10-11.5 \mathrm{~cm}$ in length. Mean length was calculated to be about $10.5 \mathrm{~cm}$, median was found to be $10.5 \mathrm{~cm}$ with a standard deviation of 2.236 .

The spleen phylogeny is highly complex because spleen has mesenchymal origin and insertion is in hematic circulation and not in lymphatic. Mammals have different types of spleen. Phylogeny of Spleen was proposed from a 'primitive type' with closed circulation (Characteristic of monotremes, insectivores and tree shrews), to 'archetypal type' with open circulation (Peculiar to mice, gerbils, bats and marsupials), further into 'blood-storing' spleens (Ungulates and carnivores) and 'defensive' spleens (Old World monkeys and the majority of rodents) 7. Monotremata, Insectivora,
Scandentia and Cetacea show a 'primitive splenic type' distinguished by a closed circulation. ${ }^{20}$

Spleen lies just beneath the left half of the diaphragm close to the 9th, 10th and 11th ribs. ${ }^{21}$ The spleen develops as a collection of mesenchymal cells in the dorsal mesogastrium. Some of these cells are contributed by the coelomic epithelium lining the mesogastrium. ${ }^{22}$ The spleen is lobulated in the foetus, but the lobules normally disappear before birth. The notches in the superior border of the adult spleen are remnants of the grooves that separated the foetal lobules. ${ }^{23}$ Wandering or ectopic spleen is a rare entity in which the spleen is located outside of its normal location. Its reported incidence in several large series of splenectomies is less than $0.5 \%$ and mainly detected in children and women between 20 and 40 years of age. The reason for the wandering spleen is the laxity of normal development of the supporting splenic ligaments, and the spleen can be found in any part of the abdomen related to the length of the vascular pedicle.

The knowledge of morphological variations of spleen is crucial for clinicians during routine clinical examination of abdomen and for surgeons for splenic and spleen-related surgeries such as laparoscopic splenectomies, for radiologists to make correct diagnosis \&also for anatomists for routine dissection. Studies related to morphometric analysis of spleen seem to be underreported and need to be carried out actively at various medical institutions/colleges for obtaining more concrete information. The implication of such projects is that it could not only enhance the fundamental knowledge but also furnishes much insight on spleen's clinical utility and significance. Knowledge of the anatomy and function of the spleen is essential for the assessment of its role in disease. The contribution of spleen to the immune response and defence against infections mandates the preservation of spleen by a conservative approach in the management of ruptured spleen. Studies on the morphometry of spleen will be of interest not only from academic point of view but also for operating surgeons and interventional radiologists. The detailed knowledge on spleen is important to avoid and prevent any complications and to obtain a good operative, as well as diagnostic intervention.

\section{CONCLUSION}

Spleen is a large encapsulated organ composed of vascular and lymphoid tissue. It is gaining widespread clinical importance because of its haematological and immunological functions in the human body. It is the need of the present era to have accurate knowledge of morphology of spleen as it reveals ample variations in its shape, size, notches \& fissures.

\section{ACKNOWLEDGEMENT}

We are grateful to Mr. Ram Ikbal Kushwaha, Sr. Technician, Department of Anatomy, for his technical assistance.

\section{REFERENCES}

[1] Fating A. A cadaveric study of morphology of human spleen. J Evolution Med Dent Sci 2017;6(63):4580-3.

[2] Blackbourne LH. Surgical recall. $5^{\text {th }}$ edn. Philadelphia, United States: Lippincott Williams \& Wilkins 2008: p. 259.

[3] Mebius RE, Kraal G. Structure and function of the spleen. Nat Rev Immunol 2005;5(8):606-16. 
[4] Onkar DP, Govardhan SA. Comparative histology of human and dog spleen. J Morphol Sci 2013;30(1):1620.

[5] Pathirana $\mathrm{TI}$, Barton $\mathrm{M}$, George $\mathrm{M}$, et al. A rare anomaly of the human spleen with nine notches associated with multiple accessory spleens. A case study, hypothesis on origin and review of clinical significance. Italian Journal of Anatomy and Embryology 2016;121(2):188-97.

[6] Sadler TW. Langman's medical embryology. Baltimore: Lippincott Williams \& Wilkins 2000: p. 277.

[7] Yildiz AE, Ariyurek MO, Karcaaltincaba M. Splenic anomalies of shape, size and location: pictorial essay. Hindawi Publishing Corporation. Article ID 321810, The Scientific World Journal 2013;2013:1-9.

[8] King H, Shumacker HB JR. Splenic studies. I. Susceptibility to infections after splenectomy is performed in infancy. Ann Surg 1952;136(2):239-42.

[9] Kato T, Tzakis AG, Selvaggi G, et al. Transplantation of the spleen: effect of splenic allograft in human multivisceral transplantation. Annals of Surgery 2007;246(3):436-46.

[10] Borley N. Spleen. In: Gray's Anatomy. 40th edn. London: Churchill Livingstone Elsevier 2008: p. 11914.

[11] Coetzee T. Clinical anatomy and physiology of the spleen. South African Medical Journal 1982;61(20):737-46.

[12] Skandalakis. Spleen. In: Skandalakis' surgical anatomy. The embryology and anatomic basis of modern surgery. Paschalidis Medical Publication Ltd., 2004;2: 1231-77.

[13] Safak AA, Simsek E, Bahcebasi T. Sonographic assessment of the normal limits and percentile curves of liver, spleen and kidney dimensions in healthy school-aged children. J Ultrasound Med 2005;24(10):1359-64.
[14] Charware PN, Belsare SM, Kulkarni YR, et al. The morphological variations of the human spleen. Journal of Clinical and Diagnostic Research 2012;6(2):159-62.

[15] Setty SRS, Katikireddi RS. Morphometric study of human spleen. Int J Biol Med Res 2013;4(3):3464-8.

[16] Lamb PM, Lund A, Kanagasabay RR, et al. Spleen size: how well do linear ultrasound measurements correlate with three-dimensional CT volume assessments? Br J Radiol 2002;75(895):573-7.

[17] Kumar V, Abbas AK, Fausto N, et al. Robbins and Cotran pathologic basis of disease. $8^{\text {th }}$ edn. New Delhi: Saunders Elsevier 2010: p. 632-5.

[18] Beauchamp RD, Holzman MD, Fafiam TC. Spleen. In: Townsend CM, Beauchamp RD, Evers BM, et al. eds. Sabiston Text book of surgery: the biological basis of modern surgical practice. Vol. 2. 17th edn. Bangalore: Saunders Elsevier 1994: p. 1679-708.

[19] Maier RV. Spleen. In: Mulholland MW, Lillemoe KD, Doherty GM, et al. eds. Greenfield's surgery: scientific principles and practice. $4^{\text {th }}$ edn. Philadelphia: Lippincott Williams \& Wilkins 2005.

[20] Udroiu I. Evolution of sinusal and non-sinusal spleens of mammals, Hystrix Italian Journal of Mammalogy 2006;17(2):99-116.

[21] Snells RS. Clinical anatomy by regions. $8^{\text {th }}$ edn. New Delhi: Wolters \& Kluwer Pvt. Ltd., 2008: p. 260.

[22] Singh IB. Development of spleen. In: Human embryology. $8^{\text {th }}$ edn. New Delhi: Macmillan India Ltd., 2007: p. 169-70.

[23] Moore KL, Persaud TVN. The developing human: clinically oriented embryology. $8^{\text {th }}$ edn. Philadelphia: WB Saunders 2009: p. 224. 